\title{
Multiple xanthogranuloma in adult : known entity, atypical association
}

\section{Introduction}

Xanthogranulomas (XGs) are a relatively common non- Langerhans cell histiocytosis. Although XGs were originally described to occur in infants and children, many cases have been documented in adults. Multiple adult XGs remain unusual, with an occasional association with hematologic malignancies. ${ }^{1}$ Association with a solid organ tumor has to our knowledge never been reported. We report a case of eruptive XG in an adult diagnosed with a phyllode tumor.

\section{Case report}

A healthy 36-year-old female patient was diagnosed with a phyllode tumor of the breast. Soon after pathologic confirmation, her surgeon and oncologist decided to decrease make a patey intervention and complete by a radiotherapy sessions. The tumor was completely excised, with negative margins and absence of lymph node metastases. A computed tomographic scan has not revealed any metastases. An atypical asymptomatic eruption that had started 4 months after being diagnosed and treated for her neoplasia. Approximately a dozen of slightly erythematous papules with an orange hue were found on the axillary region, trunk, abdomen, and thighs (Figures $1 \& 2$ ). Mucous membranes were normal, as was the review of systems.
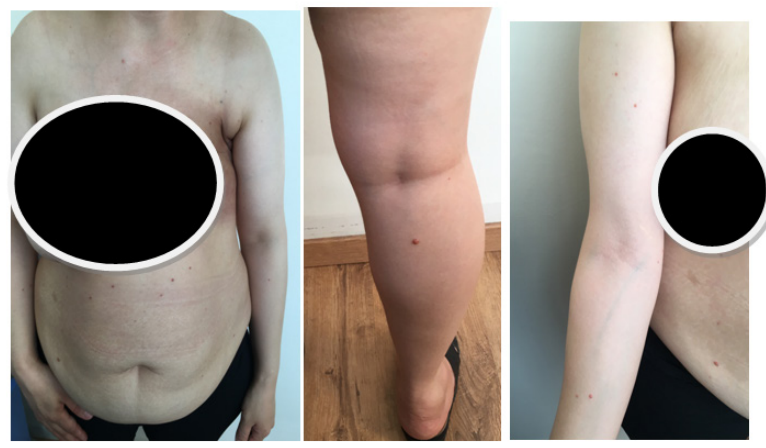

Figure I Approximately a dozen of slightly erythematous papules with an orange hue were found on the axillary region, trunk, abdomen, and thighs.

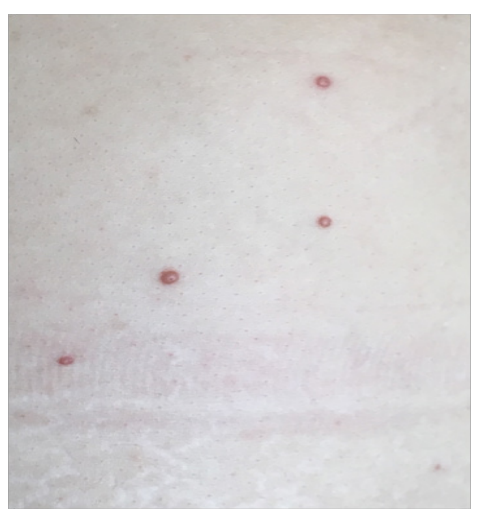

Figure 2 Multiple orange papules
Volume 9 Issue 3 - 2018

A Nassiri, Z Douhi, N Aqil, H Baybay, FZ
Mernissi
Hassan II hospital, Morocco

Correspondence: Aicha Nassiri, hassan II hospital, road of sidi hrazem, FES, Morocco, Tel +2I20650599689;

Email aichanassiri6@gmail.com

Received: February 27, 2018 | Published: May 10, 2018

At this point, our differential diagnosis included eruptive xanthomas, eruptive histiocytomas, and XG. A biopsy was performed and showed an infiltrate of histiocytes in the dermis with eosinophilic cytoplasm and Touton giant cells (Figure 3).

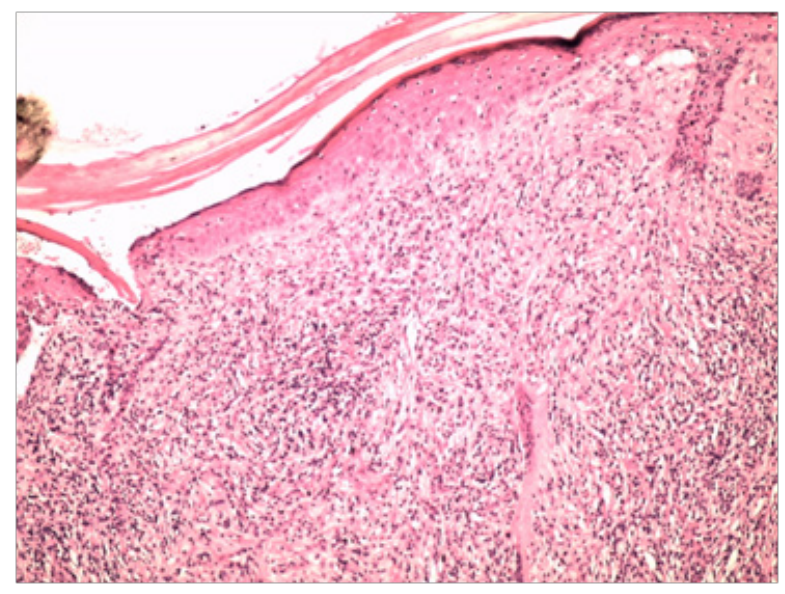

Figure 3 Fusocellular prolifération + lymphocytes $+s$ neutrophiles + giant cells.

This was compatible with $\mathrm{XG}$ of the juvenile type. A complete blood count, hepatic and renal function tests, a lipid profile, protein electrophoresis, and chest radiography were performed and the results considered within normal limits. The patient was also referred to ophthalmology, with no abnormal findings.

\section{Discussion}

$\mathrm{XG}$ represents the most common form of non-Langerhans cell histiocytosis. It is predominantly a disease of infancy and early childhood, although adults may also be affected. In both populations, patients present with yellow-brown domed papules and nodules that are widely distributed on the upper body. Approximately two thirds of juvenile and adult XG have a predilection for the head and neck region, in contrast to our case, in which the lesions were located predominately on the trunk. ${ }^{2,3}$ Two clinical variants of XG can be distinguished: the small papular form and the large nodular form. 
An atypical molluscum contagiosum-like morphology was also recently described.1 The most frequent adult presentation of $\mathrm{XG}$ remains a solitary nodule. 3 Multiple adult XGs, as in our case, are a rare entity, with only few cases reported in the literature.

Multiple articles highlight the benign natural history of adultonset XG. ${ }^{4}$ In the vast majority of cases, no associations are found. ${ }^{3,5}$ To date, there have been arround 7 cases of multiple adult XGs developing in the context of hematologic malignancy and 1 in the setting of follicular lymphoma. ${ }^{1,6}$ Hematologic conditions reported in association with adult XG include essential thrombocytosis, chronic lymphocytic leukemia, large B cell lymphoma, and monoclonal gammopathy.

The development of XG lesions can occur before, during, or after presentation of the hematologic disorder. In

contrast, the association of $\mathrm{XG}$ and juvenile chronic myelogenous leukemia in children is well documented. Children with neurofibromatosis type 1 and XG have been estimated to have 20to 32-fold higher risk for chronic myelogenous leukemia. ${ }^{7}$ This latter association has never been reported in adults. Shoo et all recommended a hematologic panel for multiple adult XGs to rule out hematologic malignancy, which seems appropriate given that approximately $30 \%$ have had this association in the literature. No drug-induced XG-like eruptions have been reported to date.

In addition, no extracutaneous multiple XG lesions in the eye, orbit, lung, liver, testis, central nervous system, or kidney have been reported in adults, in contrast to the well-documented such lesions in the pediatric population of patients. Histologically, XG in adults is identical to juvenile XG.3 Currently, the etiology of XG is still unknown, but most researchers believe that $\mathrm{XG}$ is a reactive granulomatous response of histiocytes to infection, physical stimuli, or unknown stimuli.

As a rule, no spontaneous resolution is noted in adult XG. However, new reports confirm cases to spontaneously

regress after a few months. ${ }^{8}$ No treatment is necessary for classic cutaneous $\mathrm{XG}$, but severe cutaneous involvement of the adult form may require treatment to hasten disease improvement. Cryotherapy has been beneficial in some cases. ${ }^{9}$ A recent publication reports potential improvement with isotretinoin within 2 months. ${ }^{5} \mathrm{XG}$ associated with malignancy tends to regress along with cancer treatment.

\section{Conclusion}

This is to our knowledge the first case of adult eruptive $\mathrm{XG}$ occurring in the setting of a phyllod breast tumor. Future followup of the patient is needed to evaluate the persistence or regression of lesions with completion of the cancer treatment. With the above review of literature, investigation of adults with multiple XG could be limited to a hematologic profile on a regular basis, but solid tumors shouldn't be neglected.

\section{Acknowledgements}

None.

\section{Conflict of interest}

There is no conflict of interest in publishing the article.

\section{References}

1. Shoo B, Shinkai K, McCalmont TH, et al. Xanthogranulomas associated with hematologic malignancy in adulthood. $J$ Am Acad Dermatol. 2008;59:488-493.

2. Hehner LP. Juvenile xanthogranulomas in the first two decades of life: a clinicopathologic study of 174 cases with cutaneous and extracutaneous manifestations. Am J Surg Pathol. 2003;27:579-593.

3. Chang S-E, Cho S, Choi J-C, et al. Clinicopathologic comparison of adult type and juvenile type xanthogranulomas in Korea. $J$ Dermatol. 2001;28:413-418.

4. Saad N, Skowron F, Dalle S, et al. Multiple adult xanthogranuloma: case report and literature review. Dermatology. 2006;212:73-76.

5. Arun A, Naskar B, Mondal PC, Pal M. Multiple generalised xanthogranuloma in adult: case report and treatment. Indian J Dermatol. 2011;56:197-199.

6. Narváez-Moreno B, Pulpillo-Ruiz A, De Zulueta-Dorado T, et al. Disseminated juvenile xanthogranuloma associated with follicular lymphoma in an adult: successful treatment with chemotherapy and rituximab. A review of the literature. Actas Dermosifiliogr. 2013;104:242246.

7. Zvulunov A, Barak Y, Metzker A. Juvenile xanthogranuloma, neurofibromatosis, and juvenile chronic myelogenous leukemia. Arch Dermatol. 1995;131:904-8.

8. Lin S-J, Chiu H-C. Adult multiple xanthogranulomas with spontaneous resolution. Acta Derm Venereol. 2003;83:157-158.

9. Konohana A, Noda J, Koizumi M. Multiple xanthogranulomas in an adult. Clin Exp Dermatol. 1993;18:462-463. 